\title{
Sharing Economy: A State-of-the-Art Survey
}

\author{
Zewei Yang, Lin Ma, Zike Zhang* \\ Alibaba Business College, Hangzhou Normal University \\ Hangzhou China 311121 \\ zkz@hznu.edu.cn
}

\begin{abstract}
The progress of mobile Internet technology has enabled the sharing economy to develop rapidly in the past decade, and it has rapidly involved many fields such as transportation, hotel, finance, consumer credit and labor market, and covers factor market (capital and labor) and product market (goods and services). The progress has an important impact on social and economic operation. Under this background, synthesizing domestic and foreign research on sharing economy, this paper systematically sorts out the evolution process of the concept of sharing economy, analyses the dimension of the definition of sharing economy type and its influence mechanism on economic growth, social progress and environmental change. Alongside that, this paper explores the problems and challenges that sharing economy may face in future, and proposed the possible research direction of the sharing economy in the future, so that arouse the domestic scholars pay attention to the sharing economy, business model and collaborative supervision research.
\end{abstract}

Keywords-Sharing Economy; Business Model; Influence Mechanism; Cooperative Supervision

\section{INTRODUCTION}

The concept of the sharing economy was first proposed in 1978 by American sociology professors Marcos Felson and Joan Spence [1]. For the first time, they pointed out that cooperative consumption and cooperative consumption behavior were the beginning of sharing economic theory. But in subsequent studies, the academic community has been controversial about the definition of "sharing economy".

Despite "collaborative consumption", "the mesh", "commercial sharing systems", "co-production", "co-creation", "access-based consumption", "product-service systems" and so on are all used to describe the synergistic characteristics in the process of the production and consumption. However, these terms do not fully explain the new feature of the contemporary "sharing economy" of "transferring the right to use resources to others for a fee so as to make more effective use of underutilized resources and make the overall utilization efficiency of resources higher". The main reason for the existence of so many definitions is that the development of the sharing economy is novel. The sharing economy is different from the traditional industrial economy, its research focus is mainly on the right to use material resources, not the ownership. This transformation has novelty, which makes it difficult for the academia to break the traditional research thinking mode, thus evolving different understandings and definition of the sharing economy. In addition, the existing research is mainly based on phenomena or case analysis, lacking a large number of reliable data analysis to support the idea, and that is easy to produce the different definitions because of the case guidance or the subjective influence of the researcher in the exploration of the current economic model.

In fact, the "sharing" behavior has already appeared among families, friends and neighbors, and has become more and more routine, such as food sharing between families and borrowing of tools between neighbors. But this kind of sharing is usually based on trust, and it is more likely to be driven by social obligation than economic benefit. Initially, the platform of sharing economy was driven by non-interest factors, such as Couchsurfing and Freecycle, which emphasized the sense of community identity and shared reciprocity within the community, far from profit-driven. However, with the change of consumption concept, especially under the impact of the 2008 financial crisis, people's consumption concept has shifted from the initial "whatever they have to own" to the focus on "the right to use material resources" and the effective use of underutilized resources. At the same time, the desire to increase income is becoming more and more urgent, prompting the "sharing" to gradually expand from people who know own the mutual trust to the stranger. From Couchsurfing to Airbnb, from Zipcar to Uber, the "sharing economy" has gradually turned into a profit-driven economic model by profiting from the mode of collecting part of the membership fee. The success of Uber and Airbnb has made the sharing economy a typical economic model of the information economy, which has attracted widespread attention and extensive discussion among scholars at home and abroad, which has led to the discussion of the "sharing" authenticity. Belk (2014) compares the characteristics of four types of authenticity sharing, pointing out that there are three main differences between sharing and pseudo-sharing: whether there is the interest motive, whether there is a feeling of community, whether there is a sense of reciprocity [2]. In contrast, the current domestic business models that use the symbolic meaning of the term "sharing", such as "sharing umbrellas", "sharing power bank", "sharing basketball", "sharing bicycles". It is more a short-term rental economy based on temporary use rights than the sharing economy.

In summary, the sharing economy should be an emerging business model that emerges with the development of the Internet and the digital economy. It refers to the use of modern information technology such as the Internet with the help of third-party platforms, and its main feature is to own the right of use, transferring the use right of underutilized resources to others for a fee, During the process, the suppliers receive corresponding returns, and the demanders use underutilized resources to create value economic models. 


\section{TYPE OF SHARING ECONOMY}

The existing literature studies has not given a unified standard for the classification of sharing economic types, and there are significant differences in type division based on different criteria. This paper will explain the types of sharing economy from three dimensions: platform type, transaction type, sharing object and domain.

\section{A. Platform type}

In the era of the traditional capitalist industry, because of the high cost of information, the scale of sharing behavior is small. It is mainly limited to small and closely connected communities. With the rise of digital technology and the Internet, the sharing platform has gradually developed, which has led to a decline in information costs and a corresponding reduction in the cost of sharing activities. The sharing economy is no longer constrained by the community and has entered enters the field of large enterprises. The original P2P (Peer-to-Peer) model has begun to shift to the B2C (Business-to-Customer) model.

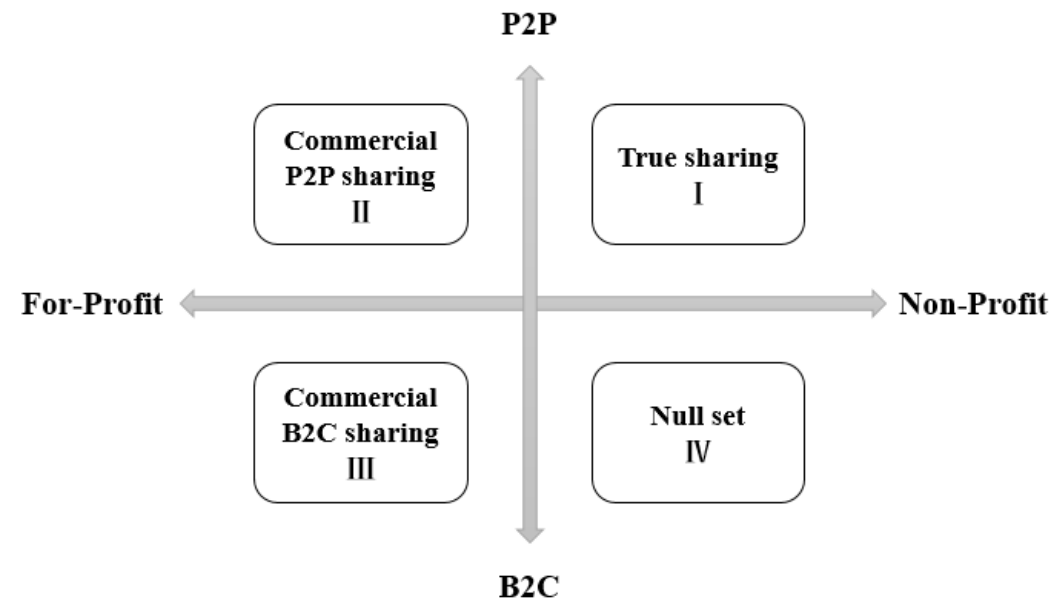

Fig. 1 Dimension division based on platform type

As shown in Figure 1, the sharing platform B2C (Business-to-Customer) and P2P (Peer-to-Peer) modes are analyzed from two main lines. One main line is classified according to whether there is interest drive, and the other is based on platform type. Expressed as a simple two-dimensional matrix: In I quadrant, it refers to the non-profit P2P type, which belongs to the real sharing mode, such as Couchsurfing and Time Banks. In II quadrant, it refers to the profit P2P type, which belongs to the commercial $\mathrm{P} 2 \mathrm{P}$ sharing mode, such as Uber and Airbnb. In III quadrant, it refers to the profit B2C type, which belongs to the sharing mode of commercial $\mathrm{B} 2 \mathrm{C}$, such as Zipcar. In IV quadrant, it refers to the non-profit B2C type, which is an empty set, because the definition of the enterprise is a profitable organization. Although the enterprise will fund the society or conduct charitable activities, the positioning is the organizational platform for the pursuit of interests.

\section{B. Transaction type}

Botsman \& Rogers (2015) divides the sharing economy case into three systems from the dimension of transaction type: Product Service System, Redistribution Markets, Collaborative Lifestyles [3]. Schor (2016) divides sharing economy

transactions into four categories based on sharing objects and user demands: recirculation of goods, increased utilization of durable assets, exchange of services, and sharing of productive assets [4]. Schor \& Fitzmaurice (2015) analyzes the types of sharing economy transactions from the perspective of

connecting and collaborating consumption, and further divides the sharing economy into four categories: commodity recycling, service exchange, asset optimization allocation and social relationship establishment [5].

\section{Sharing objects and domains}

The rapid development of the sharing economy has penetrated into various fields such as transportation, accommodation, and finance, and so on, and has effectively promoted industry innovation and upgraded industrial transformation. This paper classifies the sharing object and industry domain characteristics, dividing the sharing economy into five categories: transportation, goods, services, space, capital, and twelve subcategories, and lists the representative applications of each category. 
TABLE I

BASED ON THE TYPE OF SHARED OBJECT

\begin{tabular}{|c|c|c|}
\hline Category & Good/service & Representative Applications \\
\hline \multirow[b]{2}{*}{ Transportation } & $\begin{array}{l}\text { Sharing } \\
\text { transportation } \\
\text { service }\end{array}$ & $\begin{array}{l}\text { Uber(USA, Sharing service);Lyft(USA, Sharing service); } \\
\text { Blablacar(France, Carpool intercity sharing service);Sidecar(USA, Carpooling } \\
\text { service);Carpooling.com(Germany, Carpooling service);Autohop(Hungary, } \\
\text { Carpooling service);Didi(China, Sharing service) }\end{array}$ \\
\hline & $\begin{array}{l}\text { Rental vehicle } \\
\text { transportation } \\
\text { service }\end{array}$ & $\begin{array}{l}\text { Zipcar(USA, Sharing rental);RelayRides(USA, Sharing rental);Car2Go(Germany, } \\
\text { Sharing rental);GoCarShare(England, Sharing rental);Getaround(USA, Sharing } \\
\text { rental);Dirvy(France, Sharing rental);SnappCar(Netherlands, }\end{array}$ \\
\hline \multirow{3}{*}{ Goods } & Second-hand goods & $\begin{array}{l}\text { Ebay(USA, Product redistribution and sharing);Craigslist(USA, Second-hand } \\
\text { product sharing);Poshmark(USA, Second-hand product sharing);Tradesy(USA, } \\
\text { Second-hand clothing sharing);Threadflip(USA, Second-hand boutique clothing } \\
\text { sharing);The RealReal(USA, Second-hand luxury sharing);Yerdle(USA, Product } \\
\text { redistribution and sharing);ThredUp(USA, Children's products sharing); } \\
\text { Kijiji(Canada, Product redistribution and sharing);Freecycle(USA, Global idle } \\
\text { product sharing);Ecomodo(England, Product redistribution and } \\
\text { sharing);Peerby(Netherlands, Product redistribution and sharing) }\end{array}$ \\
\hline & Rental goods & $\begin{array}{l}\text { Rentez-Vous(France, clothing rental sharing);Rent the Runway(USA, Clothing } \\
\text { rental sharing);LE TOTE(USA, } \\
\text { Clothing rental sharing);Open Shed(Australia, product rental sharing);Chegg(USA, } \\
\text { books rental sharing);Pleygo(USA, Toy rental sharing);Rockbox(USA, Jewelry } \\
\text { rental sharing) }\end{array}$ \\
\hline & Customized goods & $\begin{array}{l}\text { Etsy(USA, Handicrafts); Quirky(USA, creative product sharing); Shapeways(USA, } \\
\text { 3D print sharing);SoundCloud(Germany, Audio sharing) }\end{array}$ \\
\hline \multirow[t]{2}{*}{ Services } & $\begin{array}{l}\text { professional } \\
\text { service }\end{array}$ & $\begin{array}{l}\text { Elance(USA, Professional outsourcing } \\
\text { outsourcing service);oDesk(USA, Professional } \\
\text { services);CrowdSpring(USA, } \\
\text { Professional creative design service) }\end{array}$ \\
\hline & Personal service & $\begin{array}{l}\text { TaskRabbit(USA, Labor service sharing);Airtasker(Australia, Labor service } \\
\text { sharing) }\end{array}$ \\
\hline \multirow{3}{*}{ Space } & $\begin{array}{l}\text { Accommodation } \\
\text { space }\end{array}$ & $\begin{array}{l}\text { Airbnb(USA, Accommodation sharing); Onefinestay(England, Accommodation } \\
\text { sharing);HomeAway(USA, Accommodation sharing);Couchsurfing(USA, } \\
\text { Accommodation sharing);Tujia(China, Accommodation sharing); }\end{array}$ \\
\hline & Office Space & $\begin{array}{l}\text { WeWork(USA, } \quad \text { Office } \quad \text { sharing);LiquidSpace(USA, } \\
\text { sharing);NextSpace(USA, Collaborative office sharing); UrWork(China, Office } \\
\text { sharing) }\end{array}$ \\
\hline & Other space & $\begin{array}{l}\text { Justpark(England, Parking space sharing);Park Tag(Germany, Parking space } \\
\text { sharing);Park Circa(USA, Parking space sharing) }\end{array}$ \\
\hline \multirow[b]{2}{*}{ Capital } & Borrowing form & $\begin{array}{l}\text { LendingClub(USA, P2P lending);Kiva(USA, P2P lending);Zopa(England, P2P } \\
\text { lending);Prosper(USA, P2P lending);GreenNote(USA, P2P lending); Iufax(China, } \\
\text { P2P lending) }\end{array}$ \\
\hline & $\begin{array}{l}\text { Crowdfunding } \\
\text { form }\end{array}$ & $\begin{array}{l}\text { Kickstarter(USA, Crowdfunding); Circleup(USA, Crowdfunding);Indiegogo(USA, } \\
\text { Crowdfunding);Crowdfunder(England, Crowdfunding);Zhongchou(China, } \\
\text { Crowdfunding) }\end{array}$ \\
\hline
\end{tabular}




\section{THE IMPACT MECHANISM OF THE SHARING ECONOMY}

\section{A. Economic influence}

From the perspective of economics, the main indicator of economic growth is GDP. However, as a key indicator of fiscal and monetary policy, GDP has serious shortcomings in measuring the benefits of the sharing economy. So, scholars study the benefits evaluation of the sharing economy from the perspective of consumer surplus and social welfare. Brynjolfsson et al (2003) studies the impact on consumer surplus from the increase in book categories of online retailers [6]. Cohen et al (2016) used Uber data, combined with its pricing method and price algorithm to evaluate the multi-point elasticity of consumers and build consumer demand curve, found that the Uber-X business in 2015 increased approximately 2.9 billion US dollars in consumer surplus in 4 US cities [7]. Benjaafar et al (2015) proves that consumers benefit from collaborative consumption through the equilibrium model of collaborative consumption, and that consumer surplus increases significantly during the sharing process [8].

The sharing economy is a new business model that is created in the Internet environment. Figure 2 compares the traditional and sharing economy business model. Under the traditional business model, the traditional intermediary organizations play the role of information dissemination, collect agency fees, and satisfy transactions between the demanders and the suppliers. The sharing business model is based on a sharing platform. The supply and demand sides follow the platform rules. The supplier transfers the right of using resources to others for a fee to obtain the platform return, and the demander pays for the commission according to the platform requirements, which is different from the traditional business model to pay the intermediary organization for money. Under the new business model, third-party Prosumers who are both producers and consumers have emerged.

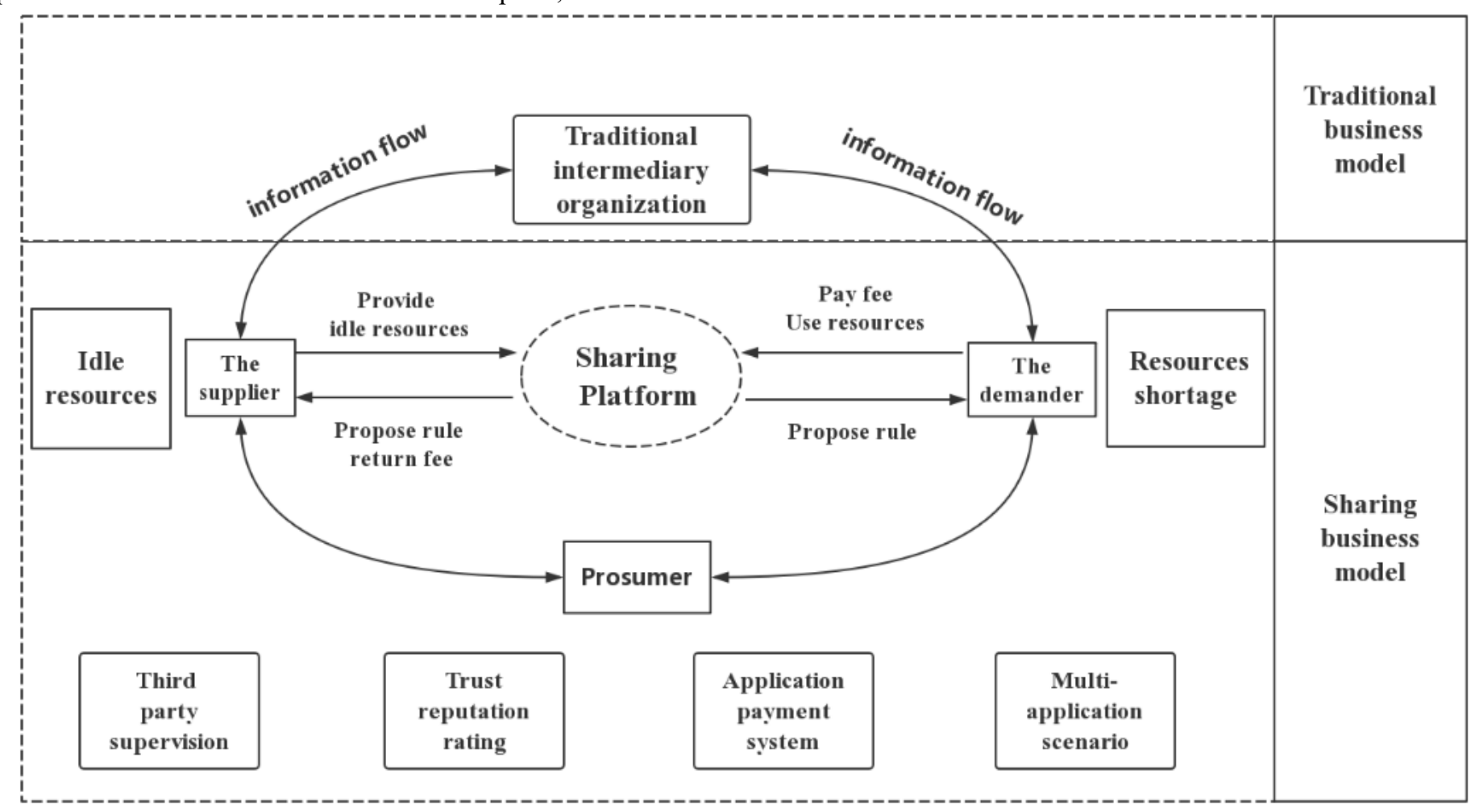

Fig. 2 Comparison of traditional business model and sharing business model

\section{B. Social influence}

The study on the social impact of the sharing economy includes not only social employment, but also social connections between people and the impact on the service industry. Facing the economic downturn and the long-term contradiction between supply and demand of employment, the rapid development of the sharing economy has changed the employment mode and structure of the traditional labor market, and market participants are flexible in self-employment. For the general social problem of rising unemployment rate and declining purchasing power at home and abroad, the development of the sharing economy undoubtedly provides individuals with the opportunity of temporary employment and creating additional income. The sharing economy brings a new family model. People can have different sources of income, and access to goods and services through a variety of low-cost channels. However, for small micro-entrepreneurs who provide services, personal medical care, insurance, and retirement may lack protection, and they need to take risks. In China, the sharing economy has penetrated into many industry industries, and the employment elasticity coefficient of participating in sharing economy activities is obviously higher than that of traditional industries. The new social division of labor promoted by the sharing economy has changed the traditional 
employment model, broadened the employment channels, and effectively alleviated the contradiction of social employment. The development of the sharing economy is very significant for increasing employment, increasing the proportion of employment, and promoting domestic employment.

The sharing economy, an emerging business model, has an impact on strengthening social connections. When Schor (2016) studied the motivations of users to participate in the sharing economy, it was found that increasing social connections was an important motivation for users' participation [4]. Schor \& Fitzmaurice (2015) pointed out that there are three main motivations for participating in the sharing economy: economic benefits, reducing ecological impact, strengthening social connections, and building social networks [5]. It is not difficult to find that the development of the sharing economy plays an important role in strengthening social connections.

\section{Environmental influence}

Faced with the increasingly depletion of material resources and deterioration of ecological environment, green and sustainable economic development model becomes more and more important. The emergence of sharing economy helps to promote the development of new sustainable business model. The environmental benefits of the sharing economy are concentrated in reducing overall resource consumption, extending product life cycle, and maximizing utilization efficiency. Martin et al (2010) pointed out that car sharing can significantly reduce the number of private cars owned [9]. According to the survey results, each car in the car sharing club can replace 9-13 private cars, and the average proportion of vehicles owned by each household decreased from 0.47 to 0.24 during the car sharing process. From the perspective of reducing waste and extending service life, product redistribution and recycling can improve utilization efficiency, reduce waste generation and carbon emissions so as to affect the environment. Chen \& Kockelman (2016) pointed out that car sharing has a significant impact on car ownership, energy use and greenhouse gas (GHG) emissions. They found that after joining the car sharing organization, the personal use of transportation energy and greenhouse gas emissions decreased by about $51 \%$ compared to when they did not participate. [10] Although some studies have shown that sharing is beneficial to the environment, Schor (2016) raises questions about the issue of sharing economy being green and sustainable. He believes that although consumer demand for new products has decreased, the ease of use has led to a significant increase in the number of uses and services [4]. In general, the development of the sharing economy is the efficient use and integration of idle resources. This is a change from ownership to use rights. By satisfying the needs of both parties through rent-and-buy, the sharing economy has greatly reduced the sales of new products. Reduce the consumption of other resources and indirectly promote the development of sustainable and circular economy.

\section{PROBLEMS AND CHALLENGES IN THE SHARING ECONOMY}

\section{A. Protection problem}

In the sharing platform, whether it is the supplier or demand side of the goods or services, its rights have not been fully protected by law. For the supply side, the sharing economy advocates a free mode of employment, that is, full freedom in the process of work, which means that suppliers (laborers) may lose basic security, lack of old-age insurance, medical insurance, and unemployment insurance. Participants in the sharing economy are mostly independent small micro-entrepreneurs, not corporate employees in the traditional business model. Although they are free to choose their working hours, they also need to bear the risk of business failure, injury, and misfortune. While the platform draws commissions, it does not provide corresponding shelter, which can be regarded as the exploitation of workers to some extent. For the demand side (consumer), the sharing economy platform needs to gradually improve social credit and credibility in the process of repeated game and information accumulation. The level of trust and reputation on the sharing platform directly affects the choice of consumers. The non-specialization of goods and services provided by the sharing economy is also likely to trigger the protection issues of the demand side. For example, the rental of houses on Airbnb does not need to meet hotel fire safety standards, Lyft drivers do not need driver's license certification and the platform does not require any qualification. Once problems arise, a series of issues, such as who is responsible for them and how to protect the rights and interests of service providers and consumers, are gradually concerned by government managers and researchers.

To sum up, the issue of the protection of the rights and interests of both parties should be taken seriously in the process of sharing economic development and supervision. In the dynamic game between sharing economy and traditional economy, the lag of laws and regulations, the lack of management of the sharing economy platform-type enterprises, the weakness of self-regulation ability, and the fulfillment of related rights and obligations all affect the protection of the rights and interests of the two parties and the healthy development of sharing economy.

\section{B. Supervision problem}

\section{1) Regulation of laws and regulations}

The novelty of the sharing economy and the lag of relevant laws and regulations make it difficult to define the legal status and responsibility boundary of platform companies. There are no clear legal provisions on the nature of the platform, industry classification, new labor-management relations, taxation of practitioners and platforms, which makes the existing laws and regulations unable to adapt to the mode of sharing economic development. In this regard, domestic and foreign research has launched a heated discussion on whether the sharing economy needs to be regulated. Liberal thinkers believe that the sharing economy does not need to be regulated. The cost of regulatory failure caused by government intervention may be much higher than the cost of market supervision, and excessive legislation and regulation will absorb or eliminate the efficiency of technological innovation. Some scholars believe that it is necessary to supervise the development of the sharing 
economy. If the unreasonable places in the existing laws and regulations are not revised, a large number of sharing economic activities will be in the gray zone. Therefore, in order to maintain the good order of the market and promote the healthy development of the sharing economy, the government must change the original regulatory model, change the regulatory thinking, innovate the regulatory concept, and change the government supervision into coordinated supervision and coordinated governance by the government and the market.

\section{2) Trust and credit rating}

The biggest feature of the sharing economy platform is that transactions are built between strangers, not based on social capital and universal trust. However, the trust mechanism is still the premise of the sharing economy. Only by establishing trust relationship with each other can we promote sharing behavior. The establishment of credit rating system is conducive to reducing information asymmetry, reducing the existence of lemon market, and forming a self-regulating model without regulatory intervention. Ghose et al (2005) pointed out that in the reputation system of the network platform, the comments published by users who participate in the reputation rating system on the platform have a significant impact on community trust. In practice, the reputation rating system is not completely reliable due to possible untrue comments and ratings [11]. Especially because the network has anonymity, if users provide false information to improve their image or intentionally discredit others, it will easily damage the interests of other users of the platform. If the anonymity of the reputation evaluation is removed, the users will be worried being retaliated rather than giving a negative evaluation. In addition to user reviews and ratings, there is a photo-based reputation rating system. The user infers the credibility of the landlord by analyzing the authenticity of the photo uploaded by the landlord. The higher the credibility of the photos, the greater the probability that the user will choose the source. Therefore, how to establish a sound credit mechanism and credit rating system is a key issue in the development of sharing economy.

\section{CONCLUSION}

The sharing economy is an emerging business model with rapid development and large scale. It involves a wide range of industries and has a huge impact on the economy, society and the environment, in stark contrast to the traditional business model. In the process of literature research, it is found that the foreign research mostly focuses on empirical research based on platform data, case-based comparative analysis, theoretical framework research based on sharing economic cases, and research reports on supply and demand sides. However, domestic research on the sharing economy are mostly limited to case analysis, business model analysis, etc., mainly based on the development status, connotation, causes, driving factors, business models, impacts factors, existing problems, and policy recommendations of the sharing economy. There are few empirical studies based on sharing platform data. Empirical research on sharing platform data at home and abroad is the focus of further research. The impact of the sharing economy on existing social and economic development, industry development, two-sided markets, employment, and environmental sustainable development should be quantified as much as possible.

\section{ACKNOWLEDGMENT}

This paper was financially supported by the National Natural Science Foundation of China (No. 61673151): Mechanisms and Dynamics of Information Spreading on Online Social Networks. Zhejiang Provincial Natural Science Foundation of China (No. LR18A050001): Method of Complex Network Reconstruction and Communication Propagation.

\section{REFERENCES}

[1] Felson M, Spaeth J L. Community structure and collaborative consumption: A routine activity approach[J]. American behavioral scientist, 1978, 21(4): 614-624.

[2] Belk R. Sharing versus pseudo-sharing in Web 2.0, The Anthropologist[J]. 2014a, 18(1): 7-23.

[3] Botsman R, Rogers R. What's mine is yours: how collaborative consumption is changing the way we live[M]. Harper Collins, 2010.

[4] Schor J. Debating the sharing economy[J]. Journal of Self-Governance \& Management Economics, 2016, 4(3): 7-22.

[5] Schor J B, Fitzmaurice C J. Collaborating and connecting: the emergence of the sharing economy[M]. Handbook of Research on Sustainable Consumption, Edward Elgar, 2015.

[6] Brynjolfsson E, Hu Y, Smith M D. Consumer Surplus in the Digital Economy: Estimating the Value of Increased Product Variety at Online Booksellers[J]. Management Science, 2003, 49(11): 1580-1596.

[7] Cohen P, Hahn R, Hall J, et al. Using big data to estimate consumer surplus: The case of uber[R]. Cambridge, The National Bureau of Economic Research, 2016, pp:1-43.

[8] Benjaafar S, Kong G, Li X, et al. Peer-to-Peer Product Sharing: Implications for Ownership, Usage and Social Welfare in the Sharing Economy[J]. 2015, https://ssrn.com/abstract=2669823.

[9] Martin E, Shaheen S A, Lidicker J. Impact of carsharing on household vehicle holdings: Results from North American shared-use vehicle survey[J]. Transportation Research Record: Journal of the Transportation Research Board, 2010, 2143(1): 150-158.

[10] Chen T D, Kockelman K M. Carsharing's life-cycle impacts on energy use and greenhouse gas emissions[J]. Transportation Research Part D Transport and Environment, 2016, 47: 276-284.

[11] Ghose A, Ipeirotis P G, Sundararajan A. Reputation premiums in electronic peer-to-peer markets: Analyzing textual feedback and network structure[C]. Proceedings of the 2005 ACM SIGCOMM workshop on Economics of peer-to-peer systems, Philadelphia, ACM, 2005, pp:150-154. 